\title{
Baclofen Pump Pseudo-Malfunctioning: Refractory Spasticity Associated to Cholecystitis
}

\author{
Bernardo Assumpção de Monaco ${ }^{1,2 *}$, GERCIVAN DOS SANTOS ALVES ${ }^{3}$ and Manoel Jacobsen Teixeira ${ }^{1}$ \\ ${ }^{1}$ Hospital das Clínicas da Faculdade de Medicina da Universidade de São Paulo, Brazil \\ ${ }^{2}$ Functional Neurosurgeon, Associação de Assistência à Criança Deficiente - AACD - São Paulo, Brazil
}

${ }^{3}$ Neurosurgery Resident, Hospital da Restauração da Universidade Federal de Pernambuco , Brazil

Submission: July 11, 2017; Published: July 31, 2017

*Corresponding author: Bernardo Assumpção de Monaco, Hospital das Clínicas da Universidade de São Paulo, Faculdade de Medicina da, Functional Neurosurgeon, Brazil, Email: bernardo.neuro@gmail.com

\begin{abstract}
There are several unleashing factors associated with spasticity worsening such as infection, pain, immobility, emotional factors, and others. Baclofen pumpis a standard treatment for selected severe spasticity cases. The authors report a case of a suspected baclofen pump malfunctioning in a paraplegic spastic patient secondary to spinal cord injury. Patient became refractory to intrathecal baclofen therapy (ITB), despite raising levels, in a complex flex mode infusion using Medtronic Infusion Pump Synchromed $2 ®$. Image investigation and catheter patency tests were performed, without obstruction. Patient became from Modified Ashwoth Scale (MAS) 0 to 4 in different times during a day. The same occurred with Penn Spams Scale. Patient was diagnosed with cholecystitis andunderwent tolaparoscopic surgery. After gallbladder resection, patient became MAS 0 and Penn 0 . Spasticity patients using ITB that become refractory to treatment should be evaluated for common unleashing factor, including cholecystitis, before suspecting of pump malfunctioning.
\end{abstract}

Keywords: Muscle spasticity; Spinal cord injuries; Baclofen, Infusion pumps; Cholecystitis, Gallbladder diseases

\section{Introduction}

Spasticity is one of the most frequent and disabling motor disorders observed in patients with central nervous system injury. Intrathecal baclofen therapy (ITB) is a good choice for severe cases, since Penn and Kroin described the first cases of ITB in 1984 [1]. Pump malfunctioning is common mostly by catheter problems, as CSF leakage, infection, catheter kink, obstruction, disconnection, dislodgment, breaking and others. Pump intrinsic malfunction is rare [2,3]. Since September 2011 Medtronic developed a new catheter, Ascenda $\AA$, whichreduces distal complications, as well as major complications in general [4]. This advances in catheter technology promoted a reduction in major pump complications from $29 \%$ to $1,1 \%$ [4].

Spasticity can be unleashed by several factors, including those responsible for autonomic hyperreflexia, such aspain, urinary tract infections, pressure ulcers, visceral distension, emotional factors, weather changes, immobility, nail lesions and others [5].

\section{Case Report}

This is a case report of a male patient, $25 \mathrm{y}, \mathrm{T} 5$ complete spinal cord injured since 2011 presenting refractory spasticity, using
ITB since 2014. Patient was receiving 90mg baclofen PO without satisfactory improvement in spasticity, with Modified Ashworth Scale (MAS) 4 and Penn 4. Patient was then tested with $50 \mathrm{mcg}$ intrathecal baclofen infusion, with great improvement, became then MAS 0 and Penn 0, during about 24h and returning to his basal state. So patient was submitted to baclofen pump implantation, with a programmable pump - Medtronic Synchromed $2 \AA$, with Ascenda ${ }^{\circledR}$ catheter.

Initial response was effective, maintaining the same response of intrathecal baclofen test after initial dose adjustment. After several months, patient became spastic again, and intrathecal dosing was adjusted in progressive higher doses. The initial response was good, but, after some weeks, patient became spastic again, with intermittent responses, varying from MAS 0 to 4 in different periods during day, the same occurred with Penn Score, varying from 0 to 4 .

After reaching $700 \mathrm{mcg} /$ day of baclofen in a simple continuous mode of intrathecal infusion, patient was submitted to a complex flex mode infusion of baclofen, and again, initial response was effective. But, after few weeks, the response fluctuations persisted. 


\section{Open Access Journal of Neurology \& Neurosurgery}

Patient was investigated for occult infection, but there was no urinary tract or lung infection, as well as no skin lesions or pain as unleashing factors.

Pump malfunctioning was considered.Before pump review surgery, patient was submitted to magnetic resonance imaging to evaluate catheter tip (located at thoracic level), if there was some inflammatory mass or granuloma, but nothing could be observed (Figure 1).

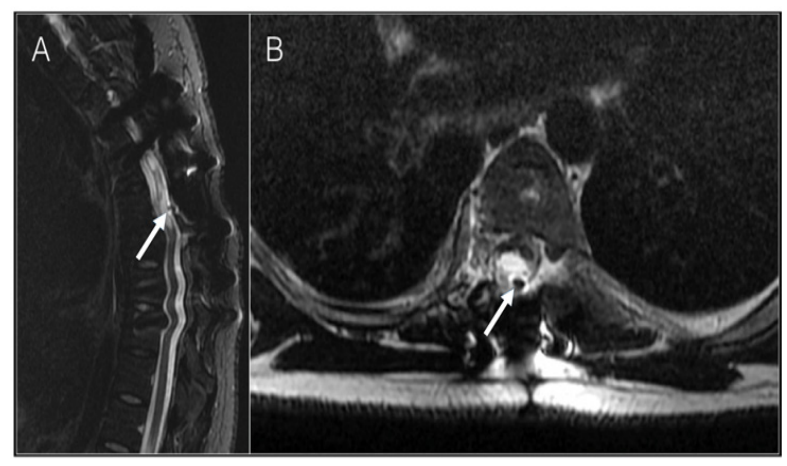

Figure 1: Catheter tip (white arrow) in magnetic resonance image showing absence of granuloma, in the caudal myelomalacia level.

Pump revision surgery was performed to investigate if there was some malfunctioning. The reservoir was emptied and volume of baclofen infusion was compatible with previously programed pump, so the medication was been delivered as programed. Medication into reservoir was changed to a new one. Old medication was submitted to culture, without any alterations, as well as cerebrospinal fluid (CSF).

Catheter patency was tested during revision surgery aspirating $10 \mathrm{~mL}$ of CSF from catheter access port, to certify that medication into catheter was completely removed. Iodine contrast was injected into catheter access port and no obstruction was observed. No pump malfunctioning could be found.

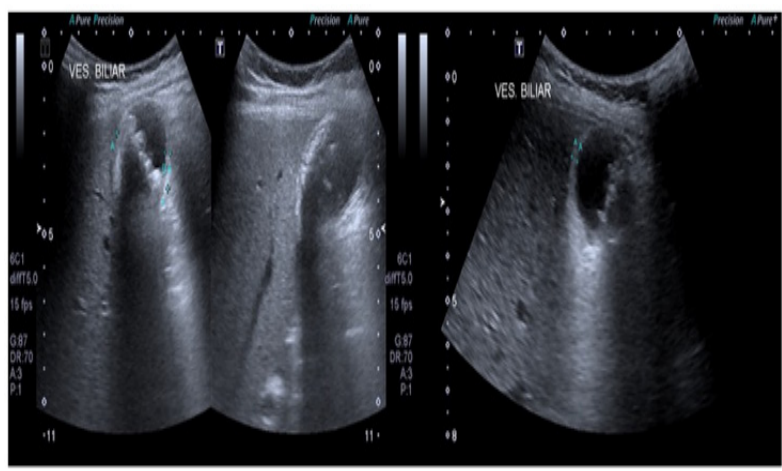

Figure 2: US showing gallstones with acoustic shadow in gallbladder and increased thickness or gallbladder wall, suggesting acute cholecystitis.
After this, baclofen dose adjustment was performed weekly until $900 \mathrm{mcg} /$ day in flex mode, and spasticity maintained the same pattern of response, with intermittent improvement, followed by recidivate symptoms. After some months of refractory response, patient presented at emergency room vomiting and with nausea, in a very intense spastic crises. Initial tests were performed, with high serum C-reactive protein, without urinary tract infection or respiratory symptoms, and without an evident factor promoting spasticity worsening. Abdominal ultra-sound showed gallstones in gallbladder and signs of acute cholecystitis (Figure 2).

Patient was submitted to video laparoscopy and cholecystectomy, without complications. After this, patient improved again with complete control of spasticity, returning to MAS 0 and Penn 0. Intrathecal baclofen dose was progressively diminished until $400 \mathrm{mcg} /$ day, and patient maintains good response after one year of follow-up.

\section{Discussion}

Spasticity can be increased by several unleashing factor, more frequently by urinary tract infection, pressure ulcers, pain, baclofen withdrawal, infections in general and psychological factors $[4,5]$. For patients with ITB, when no aggravating factor can be found, intrathecal baclofen dose should be increased. It was performed ITB increase of 10 to $15 \%$ per week. Individual flex rate baclofen infusion is preferred than simple continuous rates, considering better CSF medication dispersion. Baclofen distribution is limited along spinal cord, and significant drug concentration gradients exist within CSF and spinal cord tissue [6]. Catheter tip position still a controversy in literature $[7,8]$, but, based on the fact that CSF concentration is more expressive around catheter tip [6], our pattern is locate catheter tip near to spinal cord injury level, unless the way is blocked.

There is a report about inflammatory mass around catheter tip in two patients with intrathecal baclofen therapy, so, this complication should be considered, not just in intrathecal morphine therapy, where granuloma is more common [9]. Magnetic resonance imaging should be considered for selected cases. Testing catheter patency without image can cause rupture of a medication cyst, threatening for the patient's security.

Once most abdominal diseases commonly presented in spinal cord injuried patients are at the right abdominal site, like cholecystitis and appendicitis [10], it is protocol in our service to implant baclofen pumps in left abdominal site, remaining the right abdominal side free for investigation by ultra-sound and possible surgical approaches (Figure 3), unless there is a contraindication. When ultra-sound cannot be performed, abdominal tomography or magnetic resonance may be necessary. Medtronic Synchromed $2 ®$ is compatible with magnetic resonance imagining respecting the guideline [11]. 


\section{Open Access Journal of Neurology \& Neurosurgery}

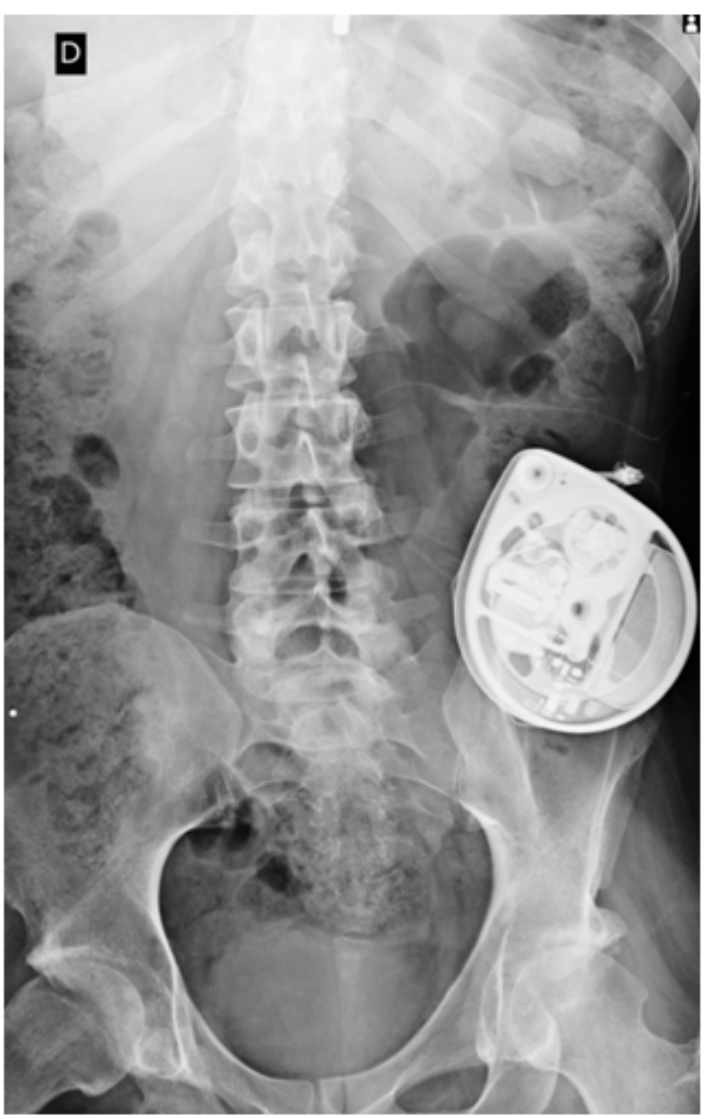

Figure 3: Baclofen pump location in left abdominal side, to avoid interfere in investigation and procedures at right abdominal side, like appendicitis and cholecystitis.

There is an increased incidence of gallbladder disease in patients with spinal cord injury, especially higher gallstones and cholecystitis incidence (17-31\%) [12-14]. Since spinal cord injured patients lack visceral sensation, their clinical manifestations of gallstones could be relatively occult. A higher proportion of these individuals may present with advanced biliary disease compared with the general population $[12,14]$. Prophylactic cholecystectomy is not indicated for spinal cord injured patients $[12,13]$. As well as asymptomatic gallstones, when detected during the evaluation of a neurological intact patient, normally does not indicate a prophylactic cholecystectomy [10]. Only about 30\% of patients with asymptomatic cholelithiasis will warrant surgery during their lifetime, suggesting that cholelithiasis can be a relatively benign condition [10].

The exact reason for higher incidence of gallstones in spinal cord injured patients is unknown. Theories try to explain about the gallbladder contractility deficit, changes in the composition and flow of bile and rapidly lose weight in these patients. Atypical symptoms and absence of classical pain in the right upper quadrant entail delay in diagnosis and often severe conditions $[12,14]$. The worsening of spasticity and spasms is a warning factor for research related diseases, as well as a comprehensive investigation of the factors listed above.

\section{Conclusion}

Spastic patients using intrathecal baclofen therapy with initial good response that become refractory despite infusion adjustments must be evaluated for unleashing spasticity factors, including gallstones and cholecystitis, before considering pump malfunctioning.

\section{References}

1. Penn RD, Kroin JS (1984) Intrathecal baclofen alleviates spinal cord spasticity. Lancet 1(8385): 1078.

2. Motta F, Antonello CE (2014) Analysis of complications in 430 consecutive pediatric patients treated with intrathecal baclofen therapy: 14-year experience. J Neurosurg Pediatr 13(3): 301-306.

3. Davanzo JR, Rizk E (2015) Baclofen overdose from possible intrinsic malfunction of SynchroMed II pump. J Neurosurg Pediatr 16(2): 232234.

4. Motta F, Antonello CE (2016) Comparison between an Ascenda and a silicone catheter in intrathecal baclofen therapy in pediatric patients: analysis of complications. J Neurosurg Pediatr 18(4): 493-498.

5. Rainov NG, Buchser E (2002) Making a case for programmable pumps over fixed rate pumps for the management of fluctuations in chronic pain and spasticity: a literature review. Neuromodulation J Int Neuromodulation Soc 5(2): 89-99.

6. Bernards CM (2006) Cerebrospinal fluid and spinal cord distribution of baclofen and bupivacaine during slow intrathecal infusion in pigs. Anesthesiology 105(1): 169-178.

7. Kroin JS, Ali A, York M, Penn RD (1993) The distribution of medication along the spinal canal after chronic intrathecal administration. Neurosurgery 33(2): 226-330.

8. Jose DA, Luciano P, Vicente V, Juan Marcos AS, Gustavo FC (2013) Role of Catheter's Position for Final Results in Intrathecal Drug Delivery. Analysis Based on CSF Dynamics and Specific Drugs Profiles. Korean J Pain 26(4): 336-346.

9. Deer TR, Raso LJ, Garten TG (2007) Inflammatory mass of an intrathecal catheter in patients receiving baclofen as a sole agent: a report of two cases and a review of the identification and treatment of the complication. Pain Med Malden Mass 8(3): 259-262.

10. Schirmer BD, Winters KL, Edlich RF (2005) Cholelithiasis and cholecystitis. J Long Term Eff Med Implants 15(3): 329-338.

11. De Andres J, Villanueva V, Palmisani S, Cerda-Olmedo G, Lopez-Alarcon MD, et al. (2011) The safety of magnetic resonance imaging in patients with programmable implanted intrathecal drug delivery systems: a 3-year prospective study. Anesth Analg 112(5): 1124-1129.

12. Moonka R, Stiens SA, Eubank WB, Stelzner M (1999) The presentation of gallstones and results of biliary surgery in a spinal cord injured population. Am J Surg 178(3): 246-250.

13. Moonka R, Stiens SA, Stelzner M (2000) Atypical gastrointestinal symptoms are not associated with gallstones in patients with spinal cord injury. Arch Phys Med Rehabil 81(8): 1085-1089.

14. Tandon RK, Jain RK, Garg PK (1997) Increased incidence of biliary sludge and normal gall bladder contractility in patients with high spinal cord injury 41(5): 682-687. 
This work is licensed under Creative Commons Attribution 4.0 Licens

DOI: 10.19080/OAJNN.2017.05.555658

\section{Your next submission with Juniper Publishers} will reach you the below assets

- Quality Editorial service

- Swift Peer Review

- Reprints availability

- E-prints Service

- Manuscript Podcast for convenient understanding

- Global attainment for your research

- Manuscript accessibility in different formats ( Pdf, E-pub, Full Text, Audio)

- Unceasing customer service

Track the below URL for one-step submission https://juniperpublishers.com/online-submission.php 